\title{
The Accuracy Comparison of Scoring Systems in the Outcome Prediction of Acute Organophosphate Poisoning
}

\author{
Soheir A. Mohamed, Marwa A. Hasb Elnabi ${ }^{1}$, Mona E. Moussa ${ }^{2}$, Hany M. Tawfik ${ }^{3}$ and Mohamed Adly ${ }^{4}$ \\ ${ }^{1}$ Forensic Medicine \& Clinical Toxicology department, Faculty of Medicine, Sohag University. \\ ${ }^{2}$ Forensic Medicine \& Clinical Toxicology department, Faculty of Medicine, Ain Shams University. \\ ${ }^{3}$ Poison Control Center, Hospitals of Ain Shams University. \\ ${ }^{4}$ Forensic Medicine \& Clinical Toxicology department, Faculty of Medicine, Cairo University.
}

Egypt.

\begin{abstract}
:
Background: Organophosphates (OP) with high morbidity and mortality are one of the most common causes of poisoning especially in developing countries. Early diagnosis and appropriate treatment is often life saving as mortality rate of OP poisoning is still high. The objective of this study is to compare the accuracy of scoring systems (the sequential organ failure assessment (SOFA) score, acute physiology and chronic health evaluation II (APACHE II) score and glasgow coma scale (GCS)) in the prediction of mortality of acute organophosphate poisoning. Methodology: A retrospective and prospective study was done on 200 patients with acute OP poisoning admitted to the Poison Control Center (PCC), hospitals of Ain Shams University in the period between 1/1/2016 and 31/12/2016. Information was collected from the sheets and computerized data base of the patients. SOFA score, APACHE II score and GCS were calculated to each patient admitted. The results were revised, coded and organized for statistical analysis.

Results: The study results revealed 180 (90\%) patients recovered and 20 (10\%) patients died. The area under the curve of receiver operator characteristic (ROC) of SOFA score was 0.995, for APACHE II score was 0.986 and compared to GCS was 0.977 with significantly higher SOFA and APACHE II scores in the died patients than in the recovered patients $(\mathrm{P}<0.001)$. As regards GCS there was statistically significant difference between recovered and died patients ( $\mathrm{P}$ $<0.001)$.

Conclusion: It could be concluded that SOFA score, APACHE II score and GCS systems can be used to predict mortality of acute organophosphate poisoning with preference to SOFA score which had the highest accuracy and predictive ability. From the previous results, our study recommends that application of SOFA score, APACHEII score and GCS are good predictors of high mortality in OP intoxicated patients which helps in proper allocation of resources particularly for intensive care unit patients.
\end{abstract}

Key words Organophosphate, APACHE II score, SOFA score, Glasgow

\section{Introduction}

$\mathrm{O}$ rganophosphates (OP) with high morbidity and mortality are one of the most common causes of poisoning especially in developing countries. Early diagnosis and appropriate treatment is often life saving as mortality rate of OP poisoning is still high (Rahimi et al., 2006).

Despite the great developments in the intensive care management, OP compounds ingestion is still a greatly contributing agent of poisoning with mortality rates 10 -
$20 \%$. Since the mortality still represents high percentage, so estimation of the severity and prognosis of the patients intoxicated by these agents is important (Lee et al., 2013; Muley et al., 2014).

There is lack of validated scoring systems to determine the severity or predicting the outcome of acute OP poisoning with highly variable history and difficulty in determining the dose and specific OP compound ingested make predicting outcome for an 
individual person inaccurate and potentially dangerous. Patients in good condition after admission can deteriorate rapidly and may need intubation with mechanical ventilation (Pore et al., 2011).

APACHE II system serves as a useful index for evaluation of the severity of poisoning due to multiple organ system involvement. And, SOFA score has been shown to have a good correlation between predicted and observed patient outcome (Williams and Gannon2009; Mahrous et al., 2011 and Kim et al., 2013). The GCS is the most widely used scale to describe the level of consciousness of the patient and is reliable for assessment and prognosis of non-traumatic coma patients (Deshpande et al., 2012; Moussa et al., 2018).

\section{Aim of the work}

The work aim is to compare APACHE II score, SOFA score and GCS accuracies in predicting the outcome of acute organophosphate poisoning.

\section{Methodology}

A retrospective and prospective study was done on 200 patients with acute OP poisoning admitted to PCC in hospitals of Ain Shams University in the period between 1/1/2016 and 31/12/2016. An approval from the Ethical Committee and the permission of the director of PCC were taken. Information was collected from the sheets and computerized data base of the patients with the confidentiality of these records, an informed consent has been obtained from each case.

\section{Patient s Selection Criteria:}

The selected patients were of both sexes with acute OP exposure. The OP poisoning diagnosis was based on history of exposure to OP compounds, toxidrome characteristic to OP toxicity, improvement of muscarinic symptoms and signs after atropine administration and low serum pseudo-cholinestrase activity (Lee, 2001)

\section{Exclusion Criteria:}

- Patients with history of sever cardiac, pulmonary, renal impairment or nephritic syndrome.

- Patients with any of the following which reduce pseudocholinestrase activity (e.g Parenchymal liver disease, acute infection, metastatic carcinoma, dermatomyositis, early pregnancy and Patients taking toxicants like carbon disulfide, cocaine and solanines or drugs like birth control pills.

The following data was collected from the sheet of each patient:

1. Sociodemographic data.

2. APACHE II score was calculated for each patient during the first 24 hours of stay by the standard methodology with range from 0 to 71 points. If a variable was measured more than once during that time, the worse value was used (Vincent and Moreno, 2010).
3. SOFA score was calculated for each patient by the standard methodology with range from 0 to 24 (Williams and Gannon, 2009).

4. GCS was measured on admission. The lowest score is 3 points and the highest score is 15 points (or 11 points with endotracheal intubation) (Mood et al., 2011).

5. Outcome of the patients:

The patients were classified according to the outcome into recovered and died patients.

\section{Statistical Analysis}

The obtained results were revised, coded and organized for statistical analysis by SPSS. Mean and standard deviation was done for numerical data. Frequency and percentage were obtained for non-numerical data. Independent t-test was used to compare between groups of outcome. Linear regression analysis was used to identify significant predictors of outcomes. P-value was considered statistically significant if $<0.05$. Standardized mortality ratio (SMR) was calculated by dividing observed hospital mortality by the predicted hospital mortality to observe the difference between expected and actual mortality rates. The ability and accuracy of the models for hospital mortality prediction were determined by examining their discrimination and calibrations. Discrimination power was assessed by the area under the curve of ROC curve and calibration by SMR. An area under the curve (AUC) of $>0.9$ was considered to be outstanding, if 0.8 to 0.9 was excellent, if 0.7 to 0.8 was acceptable, and was considered poor if $<0.7$ (Mahrous et al., 2011).

\section{Results}

The total number of the patients was 200 patients of acute OP poisoning admitted to the Poison Control Center (PCC) in hospitals of Ain Shams University. Most of patients were belonging to teenager and middle age group (18 - 40 years) representing $44.5 \%$ of the patients in the study. Females affected more than males and patients from urban areas were more than rural areas. Acute organophosphate intoxication was found commonly occurring in unemployed (43\%) followed by students (23\%) and lastly housewives (12\%) (table, 1).

As shown in table (2), the outcome of the patients was as the following: 180 patients were recovered representing about (90\%) and 20 patients were died representing about (10\%). As regards hospital site admission, $57.5 \%$ of patients were in inpatient unit and $42.5 \%$ were in ICU. As regard complications developed, $24 \%$ of the patients in the present study developed complications.

Regarding the relationship between actual survival and predicted mortality by APACHE II score, SOFA score and GCS according to their best cutoff point, table (3) shows that $37(18.5 \%)$ patients were predicted to die by APACHE II score, 28(14\%) of them were predicted to die by SOFA score and 22(11\%) 
patients were predicted to die by GCS. Actually $20(10 \%)$ patients died. There was significant statistical difference between recovered and died patients as regards GCS, APACHE II score and SOFA Score where patients who died had high values of APACHE II score, high values of SOFA Score and low values of GCS than recovered patients.

APACHEII score, SOFA score and GCS could be used as predictors of outcome of acute organophosphorus poisoning, (table, 4). As shown in table (5), the actual mortality rate was $10 \%$ and Predicted mortality rates were $18.5 \%, 14 \%$ and $11 \%$ for APACHEII score, SOFA score and GCS, respectively.
SMR for APACHEII score was 0.54 , for SOFA score 0.71 and for GCS was 0.90 .

As shown in table (6) and figures (1, 2 and 3), APACHE II score at cut off value $>10$ had corresponding sensitivity $100 \%$ and specificity 90.56\% ( $\mathrm{P}<0.001)$. On the other hand SOFA score at cut off $>5$ had sensitivity $100 \%$ and specificity 90.56\% (P<0.001) and GCS at cut off value $\leq 8$ had sensitivity $85 \%$ and specificity $97.22 \%$ (P $<0.001)$. SOFA score had the largest AUC and there was statistically significant difference when compared with APACHE II score and GCS.

Table (1): Number and percentage of the studied patients as regard sociodemographic data (age, sex, residence and occupation)

\begin{tabular}{|c|c|c|c|}
\hline \multicolumn{2}{|l|}{ Sociodemographic variables } & Number & Percentage \% \\
\hline Residence & Urban & 126 & $63 \%$ \\
\cline { 2 - 4 } & Rural & 74 & $37 \%$ \\
\hline Occupation & Unemployed & 86 & $43 \%$ \\
\cline { 2 - 4 } & Student & 46 & $23 \%$ \\
\cline { 2 - 4 } & Housewife & 24 & $12 \%$ \\
\cline { 2 - 4 } & Civil employer & 22 & $11 \%$ \\
\cline { 2 - 4 } & Manual worker & 14 & $7 \%$ \\
\cline { 2 - 4 } & Farmer & 8 & $4 \%$ \\
\hline
\end{tabular}

SD: Standard deviation

Table (2): Outcome, hospital site admission and complications developed of the studied patients in the present study.

\begin{tabular}{|c|c|c|c|}
\hline \multicolumn{2}{|c|}{ Total number=200 } & Number & Percentage \% \\
\hline \multirow{2}{*}{ Outcome } & Discharged & 180 & $90 \%$ \\
\cline { 2 - 4 } & Died & 20 & $10 \%$ \\
\hline $\begin{array}{c}\text { Hospital site } \\
\text { admission }\end{array}$ & Inpatient & 115 & $57.5 \%$ \\
\hline $\begin{array}{c}\text { Complications } \\
\text { developed }\end{array}$ & ICU & 85 & $42.5 \%$ \\
\cline { 2 - 4 } & Non complicated & 152 & $76 \%$ \\
\hline
\end{tabular}

ICU: intensive care unit

Table (3): Scoring systems of the studied patients in the present study.

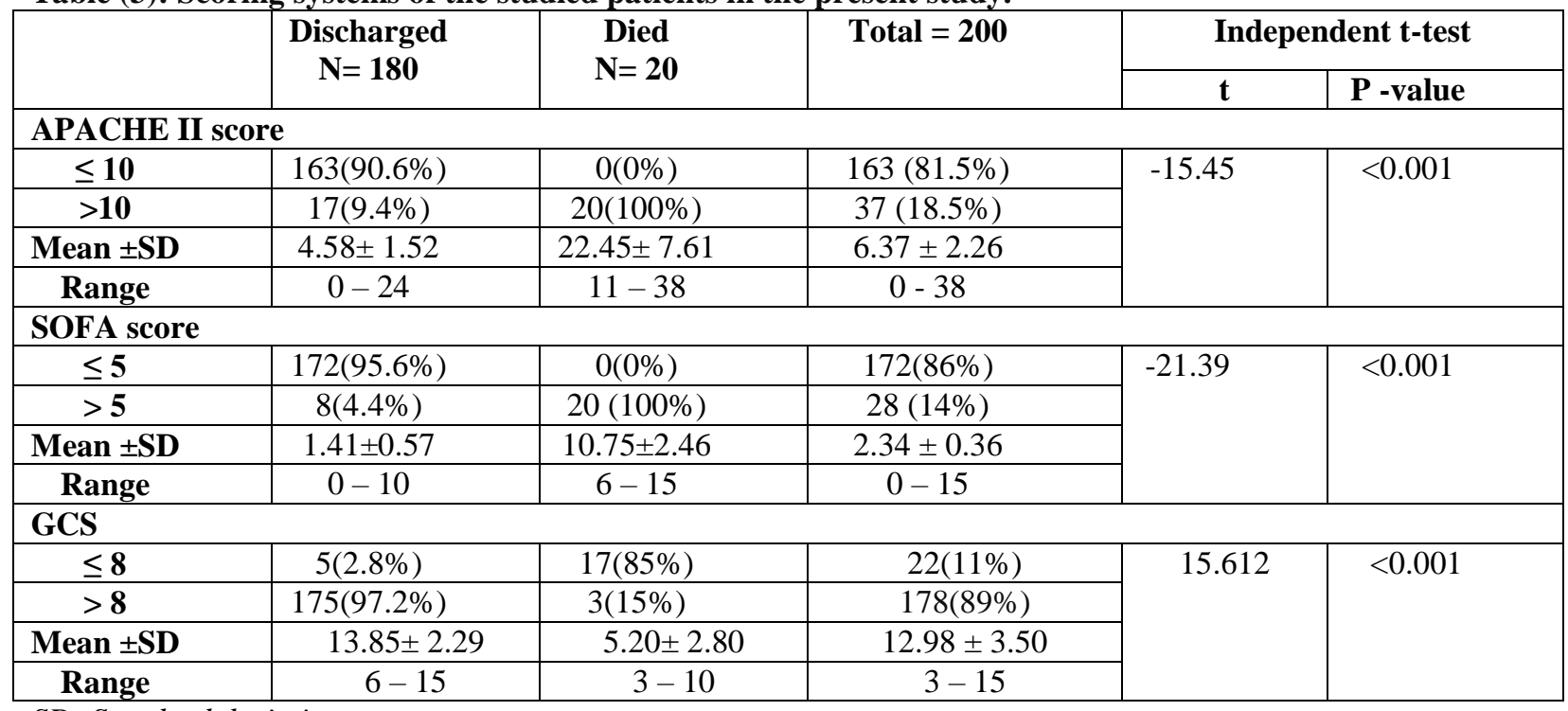

SD: Standard deviation 
Table (4): Linear regression analysis of APACHEII score, SOFA score and GCS to detect predictors of outcome.

\begin{tabular}{|c|c|c|c|c|}
\hline \multirow{2}{*}{ inear regression analysis } & \multicolumn{2}{|c|}{ Unstandardized C. } & Standardized C. & \multirow{2}{*}{ P- value } \\
\cline { 2 - 4 } & $\mathbf{B}$ & Standard Error & Beta & \\
\hline APACHE II & -0.019 & 0.004 & -0.461 & $<\mathbf{0 . 0 0 1}$ \\
\hline SOFA & 0.101 & 0.007 & 1.192 & $<\mathbf{0 . 0 0 1}$ \\
\hline GCS & -0.062 & 0.004 & -0.725 & $<\mathbf{0 . 0 0 1}$ \\
\hline
\end{tabular}

C: Coefficients

Table (5): Actual mortality rate, predicted mortality rate and SMR of the scoring systems.

\begin{tabular}{|c|c|c|c|}
\hline Model & $\begin{array}{c}\text { Actual } \\
\text { mortality rate }\end{array}$ & $\begin{array}{c}\text { Predicted } \\
\text { mortality rate }\end{array}$ & SMR \\
\hline APACHE II & $10 \%$ & $18.5 \%$ & 0.54 \\
\hline SOFA & $10 \%$ & $14 \%$ & 0.71 \\
\hline GCS & $10 \%$ & $11 \%$ & 0.90 \\
\hline
\end{tabular}

SMR: standardized mortality ratio.

Table (6): The receiver operating characteristic curve of the scoring systems.

\begin{tabular}{|c|c|c|c|c|c|c|}
\hline Variable & Cut off & AUC & Sensitivity & Specificity & Accuracy rate & 95\% CI \\
\hline APACHE II score & $>\mathbf{1 0}$ & 0.986 & 100 & 90.56 & $98.6 \%$ & $0.97-1.00$ \\
\hline SOFA score & $>\mathbf{5}$ & 0.995 & 100 & 90.56 & $99.5 \%$ & $0.98-1.00$ \\
\hline GCS & $\leq \mathbf{8}$ & 0.977 & 85.00 & 97.22 & $97.7 \%$ & $0.95-0.99$ \\
\hline
\end{tabular}

AUC: Area under the curve

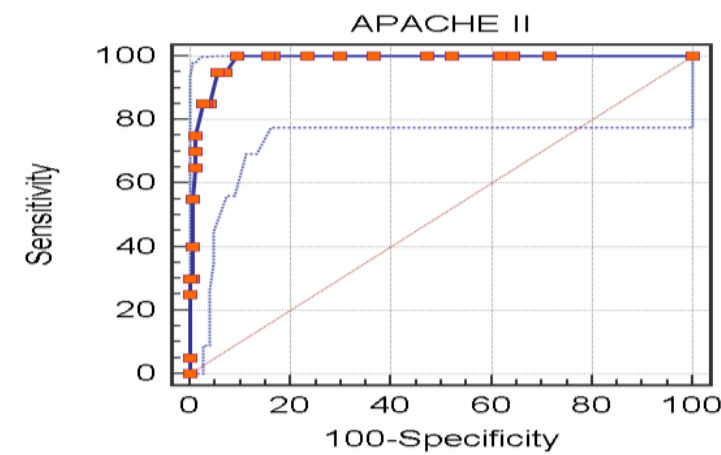

Figure (1): The ROC of APACHE II score.

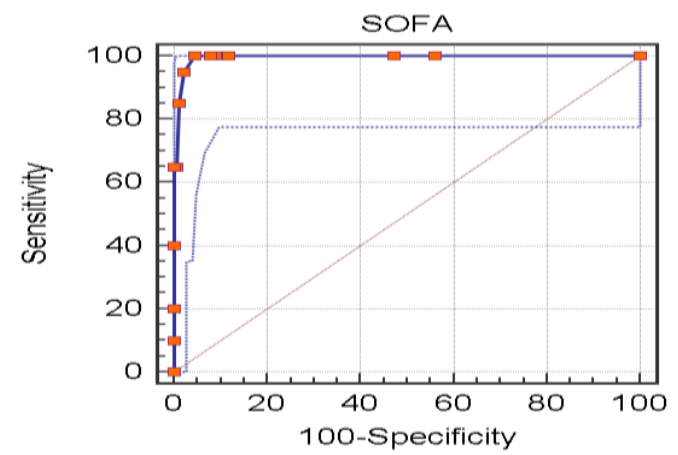

Figure (2): The ROC of SOFA score.

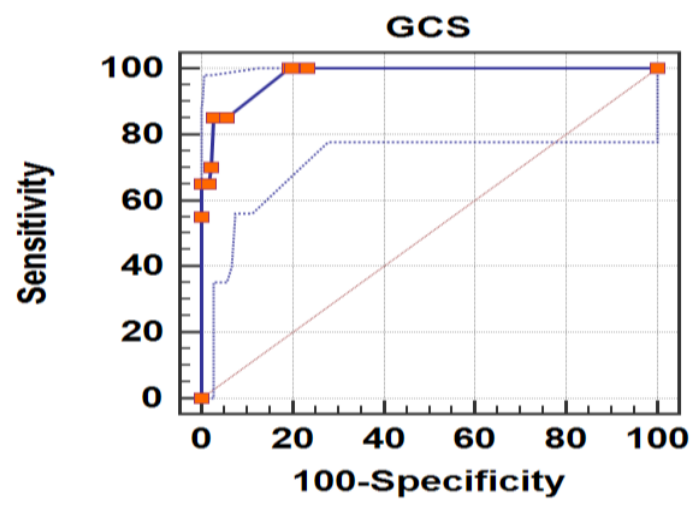

Figure (3): The ROC of GCS 


\section{Discussion}

Organophosphate poisoning is a health problem and may be associated with morbidity and mortality in developing countries.The aim of this study is to compare APACHE II score, SOFA score and GCS accuracies in the outcome prediction of acute organophosphate poisoning. In the current study $44.5 \%$ of patients were belonging to age from 18 to 40 years.

This finding was similar to that of Ahmed et al., (2014) and Banday et al., (2015) in which the incidence was highest in patients aged less than 40 years. There were only $2 \%$ of all patients in the study above 60 years old and this was in agreement with Chintale et al., (2016).

This could be explained by the vulnerability to various emotional conflicts that can happen during this phase (teenager and middle age groups) of life in which the people are most ambitious and productive (Banday et al., 2015). In the current study females were more affected. This was in agreement with Chaturvedi et al., (2014) and Gündüz et al., (2015) study in which females were also affected more than males.

On contrary to many other studies males were more affected than females (Muley et al., 2014; Sumathi et al., 2014; Ghaniger et al., 2016).

Causes of female predominance in this study may be attributed to emotional liability of female to life stress and strains in our society than male. Also OP compounds are available in the home as a household product (Z'gambo et al., 2016).

In the current study, the majority of cases came from urban areas. The same result was reported by Thomas et al., (2002), other studies in developing countries, showed that OP insecticides are common suicidal agents among adolescents especially in urban areas (Gunnell and Eddleston, 2003).The reverse was reported by Hassan and Madboly, (2013) and Bilal et al., (2014) where most of patients came from rural areas. In the present study $43 \%$ of cases were unemployed followed by students then housewives. Saadeh et al., (1996) found that unemployment constituted $43 \%$ in patients with OP poisoning. On the other hand, in the study performed by Rehiman et al., (2008) house wives and students were the most common acutely organophosphate intoxicated patients. The present study showed that the actual mortality in OP poisoning was $10 \%$. Predicted mortality rates were $18.5 \%, 14 \%$ and $11 \%$ for APACHEII score, SOFA score and GCS, respectively.

This was in agreement with results reported by Bilal et al., (2014) where death was observed in 10\% cases. This ratio was close to this obtained by Godhwani et al., (2004) where it was 12\%. Yamashita et al., (1997) reported a higher rate of $25 \%$, while Dharmani and Jaga, (2005) reported that mortality of OP poisoning was $46 \%$.

There was statistically significant association between high APACHEII score, high SOFA score and low GCS and severity of OP poisoning. This was in agreement with Singh et al., (2011) and Kim et al., (2013) studies in which non survivors had higher APACHE II score and SOFA score than survivors. Also, Jabalameli et al., (2006) reported that died patients had highest APACHE II Score and correlated with the occurrence of complications in OP poisoning.

These results also go with those of Kang et al., (2009) who reported that The APACHE II score was high in died patients in acute organophosphate poisoning and those who had complications especially respiratory failure. Also, this was similar to findings of Vosylius et al., (2005) who reported higher SOFA score in the nonsurvivors than the survivors and the development of more severe organ dysfunction was strongly associated with mortality. Also, Budhathoki et al., (2009) mentioned that GCS less than 8 had been more associated with mortality in children presenting with poisoning more frequently.

Moreover Russell and Shobhan, (2009) found that a GCS of 8 or less is a useful guide for the requirement of endotracheal intubation where the cause of coma is poisoning and Muley et al., (2014) mentioned that GCS $\leq 12$ had been significantly associated with morbidity. By using linear regression analysis with the scoring systems studied in the current work it was found that APACHEII score, SOFA score and GCS were highly significantly increased with death hence could be used as predictors of outcome. This was similar to results of Sam et al., (2009) and Sumathi et al., (2014).

Kim et al., (2013) stated that SOFA score is significantly associated with mortality and has strong discriminative power for predicting mortality. APACHE II score is a simplified physiological score in prediction and assessment of the severity and mortality of OP poisoning and GCS can be applied in the prediction of the mortality in OP poisoning (Sam et al., (2009). Similarly, Davies et al., (2008) reported that GCS was effective at outcome prediction in acute organophosphate intoxication and patients presenting with a GCS $\leq 13$ need intensive monitoring and treatment. SMR for APACHEII score was 0.54, for SOFA score 0.71 and for GCS was 0.90 and the AUC was 0.986 for APACHE II score, was 0.995 for SOFA score and compared to GCS was 0.977. Also, the accuracy rate of SOFA score (99.5\%) was higher than that of APACHE II score (98.6\%) and GCS (97.7\%).

These results go with those of Sumathi et al., (2014) where the area under the curve was 0.896 for SOFA score and was 0.716 for APACHE II score and the accuracy rate of SOFA score was higher than that of APACHE II score. Also, Bilgin et al., (2005) found that the standardized mortality rates were 0.87 and 1.0 for APACHE II and GCS, respectively and AUC for APACHE II score was 0.93 and for GCS was 0.90 . So all can predict the outcome of organophosphorus poisoning but SOFA score had the highest accuracy and 
predictive ability followed by APACHE II score while GCS was the least one.

This was in agreement with Baradari et al., (2016) and Shabir and Maqbool,(2017) where their studies recorded that SOFA score is able to predict the outcome significantly. Also, Kim et al., (2013) concluded that SOFA score is more useful in predicting mortality, easier and simpler than APACHE II score.

\section{Conclusion}

SOFA score, APACHE II score and GCS systems can be used to predict in-hospital mortality of acutely organophosphate intoxicated patients with preference to SOFA score which had the highest accuracy and predictive ability.This helps in proper allocation of resources particularly for intensive care unit patients.

\section{References}

Ahmed K., Sainath C. and Ahmed P. (2014): A cross sectional study of estimation of plasma pseudo cholinesterase and its correlation to mortality among organophosphorous poisoning patients. Indian Journal of Basic and Applied Medical Research, 3(3): 285-291.

Banday T., Tathineni B. and Desai M. et al. (2015): Predictors of morbidity and mortality in organophosphorus poisoning: A case study in rural hospital in Karnataka. Am J med sci; 7(6): 259-265.

Baradari A., Firouzian A. and Davanlou A.et al. (2016): Comparsion of patient's' admission, mean and highest SOFA scores in prediction of ICU mortality. Mater Sociomed, 28(5):343-347.

Bilal M., Khan Y. and Ali S. et al. (2014): The pattern of organophosphorus poisoning and its short term outcomes in various socioeconomic groups. KJMS; 7(1): 11-16.

Bilgin T, Camdeviren H and Yapici D. e al. (2005): The comparison of the efficacy of scoring systems in organophosphate poisoning. Toxicol. Industr. Health, 21(7-8):141-146.

Budhathoki S., Poudel P. and Shah D. et al. (2009): Clinical profile and outcome of children presenting with poisoning or intoxication: a hospital based study. Nepal. Medical College Journal, 11(3): 170-175.

Chaturvedi A., Dutta S. and Sarkar S. et al. (2014): Prevalence of hyperamylasemia and acute pancreatitis in organophosphate poisonings. Journal of dental and medical sciences, 13(1):5962.

Chintale K., Patne S. and Chavan S. (2016): Clinical profile of organophosphorus poisoning patients at rural tertiary health care centre. International Journal of Advances in Medicine, 3(2):268-274.

Davies J, Eddleston M, Buckley N et al., (2008): Predicting Outcome in Acute Organophosphorus Poisoning with a Poison Severity Score or the Glasgow Coma Scale
QJM. 101(5):
doi:10.1093/qjmed/hcn014.

$371-379$.

Deshpande A, Gaikwad N and Deshpande S (2012): Study of Glasgow Coma Scale Score and QTc Interval in Prognosis of Organophosphate Compound Poisoning. Indian Journal of Clinical Medicine.3: 25-31.

Dharmani C. and Jaga K. (2005): Epidemiology of acute organophosphate poisoning in hospital emergency room patients. Rev Environ Health; 20(3): 215247.

Ghaniger M., Hemamalini G. and Sanjana K. (2016): Prevalence of acute pancreatitis in organophosphate poisoning in correlation with elevated serum amylase and lipase level in a tertiary care hospital. Sch.J.App.Med.Sci; 4(3):963-965.

Godhwani S., Godhwani S. and Tulsiani K. (2004): Management of organic insecticide poisining in intensive care unit .Indian J. Anaesth; 48(4): 295393.

Gündüz E., Dursun R. and Icer M. et al. (2015): Factors affecting mortality in patients with organophosphate poisoning. Journal of Pakistan Medical Association, 65(9): 967-972.

Gunnell D. and Eddleston M. (2003): Suicide by intentional ingestion of pesticides: a continuing tragedy in developing countries. International Journal of Epidemiology, 32:902-909.

Hassan N. and Madboly A. (2013): Correlation between serum creatine phosphokinase and severity of acute organophosphorus poisoning: A Prospective clinical study (2012-2013).Journal of Environmental Science, Toxicology and Food Technology, 4(5): 18-29.

Jabalameli M., Eizadi N. and Saghaie M. (2006): Predictive outcome of toxicity with organophosphate based on APACHE II scoring system in intensive care unit. European journal of anaesthesiology, 23:206.

Kang E., Seok S. and Lee K. et al. (2009): Factors for determining survival in acute organophosphate poisoning. Korean J Intern Med; 24: 362-367, doi: 10.3904/kjim.2009.24.4.362

Kim Y, Yeo J, Kang $M$ et al., (2013): performance assessment of the SOFA, APACHE II scoring system, and SAPS II in Intensive Care Unit Organophosphate poisoned patients. J Korean Med Sci. 28:1822-1826.

Lee J., Lee Y. and Park Y. et al. (2013): The difference in C-reactive protein value between initial and 24 hours follow-up (D-CRP) data as a predictor of mortality in organophosphate poisoned patients. Clinical Toxicology, 51:29-34.

Lee P (2001): Clinical features of patients with acute organophosphate poisoning requiring intensive care. ICU Med; 27:694-699.

Mahrous A, Mohy K, Amany A et al., (2011): Comparison of the accuracy of two scoring 
systems in predicting the outcome of organophosphate intoxicated patients admitted to intensive care unit (ICU). Egyptian Journal of Forensic Sciences.1: 41-47.

Mood N., Sabzghabaee A. and Yadegarfar G. et al. (2011): Glasgow coma scale and its components on admission: are they valuable prognostic tools in acute mixed drug poisoning? Critical Care Research and Practice; 952956,doi:10.1155/2011/952956.

Moussa M., Soheir A., Maha A. et al., (2018): Predictive Value of Triage Vital Signs and Conscious Level for Outcome Evaluation in Acutely Organophosphate Poisoned Patients. Ain Shams Journal of Forensic Medicine and Clinical Toxicology, 31: 33-40.

Muley A., Shah C. and Lakhani J. et al. (2014): To identify morbidity and mortality predictors in acute organophosphate poisoning. Indian J Crit Care Med; 18:297-300.

Pore N., Pujari K. And Jadkar S. (2011): Organophosphorus poisoning. International Journal of Pharma and Bio Sciences, 2(4): 604612.

Rahimi R., Nikfar S. and Abdollahi M. (2006): Increased morbidity and mortality in acute human organophosphate-poisoned patients treated by oximes: a meta-analysis of clinical trials. Hum Exp Toxicol; 25(3): 157-213.

Rehiman S., Lohani S. and Bhattarai M. (2008): Correlation of serum cholinesterase level, clinical score at presentation and severity of organophosphorous poisoning. J Nepal Med Assoc; 47(170):47-52.

Russell D. and Shobhan. T. (2009): Decreased glasgow coma scale score does not mandate endotracheal intubation in the emergency department. J. Emerg. Med; 37(4):451-455.

Saadeh A., al-Ali M. and Farrakhan M. (1996): Clinical and sociodemographic features of acute carbamate and organophosphate poisoning: a study of 70 adult patients in North Jordan .J Toxicol Clin Toxicol; 34: 45-51.
Sam K., Kondabolu K. and Pati D., et al. (2009): Poisoning severity score, APACHE II and GCS: Effective clinical indices for estimating severity and predicting outcome of acute organophosphorus and carbamate poisoning. J Forensic Leg Med; 16:239-286.

Shabir A. and Maqbool M. (2017): Accuracy of SOFA score in predicting outcome in medical patients with various diagnosis in intensive care unit. International Journal of Contemporary Medical Research,4(1):77-83.

Singh O., Javari Y. and Juneja D. et al (2011): Profile and outcome of patients with acute toxicity admitted in intensive care unit: Experiences from a major corporate hospital in urban India. Indian J Anaesth; 55:370-374.

Sumathi M., Kumar S. and Shashidhar K. et al. (2014): Prognostic significance of various biochemical parameters in acute organophosphorus poisoning. Toxicol Int; 21(2): 167-171.

Thomas M., Anandan S. and Kuruvilla P. (2002): Profile of hospital admissions following acute poisoning experiences from a major teaching hospital in South India. Adverse Drug React Toxicol; 21(6):515-517.

Vincent J. and Moreno R. (2010): Clinical review: Scoring systems in the critically ill. Critical Care, 14:207.

Vosylius S., Sipylaite J. and Ivaskevicius J. (2005): Sequential Organ Failure Assessment score as the determinant of outcome for patients with severe sepsis. Croat Med J; 45:715-720.

Williams L and Gannon J (2009): Use of the SOFA score in pandemic influenza - a prospective study. JICS.10:179-182.

Yamashita M., Tanaka J. and Ando Y. (1997): Human mortality in organophosphate poisonings. Vet Hum Toxicol; 39(2):84-85.

Z'gambo J., Siulapwa Y. and Michelo C. (2016): Pattern of acute poisoning at two urban referral hospitals in Lusaka, Zambia, BMC Emergency Medicine; 16(2): 2-8 DOI: 10.1186/s12873-016-0068-3 


\section{الملخص العربي}

\section{مقارنة دقة أنظمة التسجيل فى التنبؤ بالنتيجة لمرضى التسمم الحاد بالمركبات الفسفورية العضوية}

سهير على محمدو مروه أحمد حسب النبى' ومنى القطب موسىَّ و هانى محمد توفبقّ ومحمد علدى؛

مقدمة البحث: تعتبرالمركبات الفوسفورية العضوية من أهم اسباب حدوث التسمم الحاد وخاصة فن البلدان النامية كما اها مسئولة عن نسبه

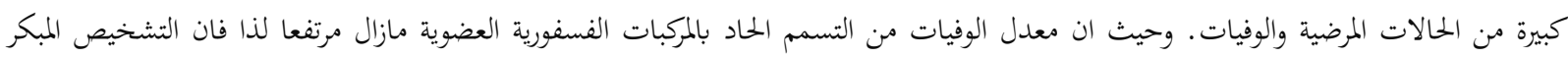
واستخدام العلاج المناسب دائما منقذين للحياه.

الهدف من الدراسة: تمدف هذة الدراسة الى مقارنة دقة أنظمة التسجيل سوفا واباتش الثانى ومقياس جلاسكو فن التنبؤ بحدوث الوفاة في

$$
\text { حالات التسمم الحاد بالمركبات الفسفورية العضوية. }
$$

طريقة البحث: تم عمل هذه الدراسة باثر رجعى ومستقبلى على . . F مريض من حالات التسمم الحاد بالمركبات الفسفورية العضوية بمركز

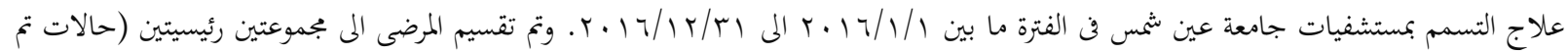
تحسنها و وفيات). وقد تم جمع البيانات من ملفات المرضى وقاعدة الملفات الالكترونية بلمكرز والتى تشمل: تطبيق انظمة التسجيل سوفا واباتش الثانى ومقياس جلاسكو.

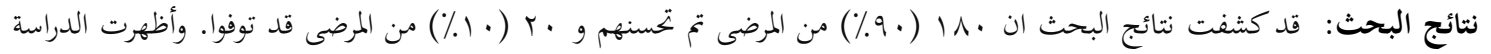

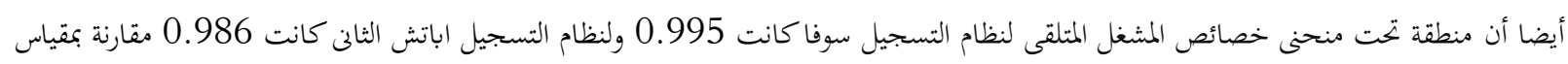

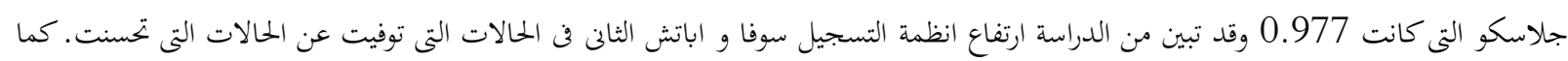

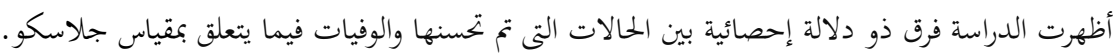

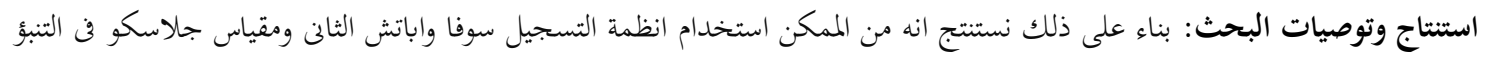

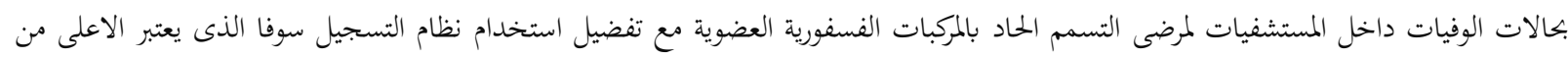

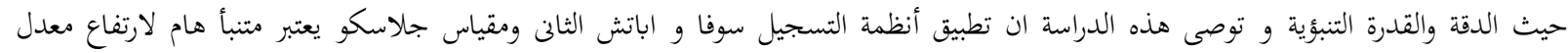
الوفيات لمرضى التسمم بالمركبات الفسفورية العضوية حيث يساعد ذلك على التخصيص الامثل للموارد خصوصًا لمرضى وحدة العناية المرّزّة.

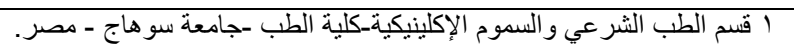

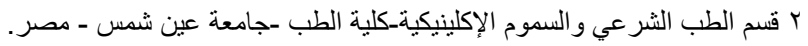

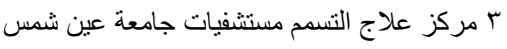

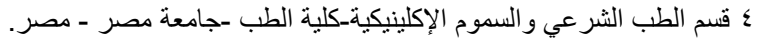

